\title{
Minimally Invasive Options to Disc SuRgery
}

\author{
Adrian M. Zachary, DO, and Joseph D. Fortin, DO \\ Consumer consciousness, the evolution \\ of non-operative specialties involved in pain \\ management, a continuing trend toward outpa- \\ tient versus inpatient procedures and cost con- \\ cerns have all generated interest in minimally \\ invasive options to spine surgery. Accompa- \\ nying this movement are the aspirations of re- \\ duced convalescence, loss of functional limita- \\ tions, lowered complications and diminished \\ costs. Although new therapies offer future \\ promise, there is currently a paucity of random- \\ ized controlled trials on these options. The fol- \\ lowing is a general review of several minimally \\ invasive options to disc surgery. \\ Keywords: IDET, Nucleoplasty, Percu- \\ taneous disc decompression, percutaneous \\ laser discectomy, automated percutaneous \\ discectomy
}

The purpose of this article is to give a general overview of several minimally invasive options to disc surgery, proposed mechanisms of action, indications, clinical results and some of the reported complications. It is not intended to be an in depth discussion of the technical aspects of performing these procedures.

\section{IDET (InTRADISCAL Electrothermal ANNULOPLASTY)}

\section{Proposed Mechanism of Action}

Although a precise mechanism for the effects of IDET is not known, several theories are currently in favor. One theory is that the resistive heating coil used produces an elevation in annular temperature sufficient to cause nociceptive fiber destruction (1). Shah et al (2) demonstrated collagen denaturation, shrinkage and coalescence with no evidence of damage to the endplates or untreated portions of the disc. Although the electrothermal coagulative effects on intradiscal nerve endings have not been determined, Bono et al (3) have demonstrated a potential zone of denervation within the annulus with this procedure. Another potential mechanism is stimulation of annular healing through cauterization of vascu-

From Spine Technology and Rehabilitation, Fort Wayne, IN. Address Correspondence: Joseph D. Fortin, DO, Spine Technology and Rehabilitation, 7230 Engle Road, Suite \#210, Fort Wayne, IN 46804. E-mail: fortin@pol.net

Funding: There was no external funding in preparation of this manuscript. lar in-growth (2) . Others believe the underlying mechanism may lie in alteration of the motion segment biomechanics due to collagen modification, though Lee et al (4) failed to show any statistically significant decrease in spinal stability.

\section{Indications}

The IDET procedure is indicated for patients with intractable low back pain from internal disc disruption with adequate maintenance of disc space height (no greater than $50 \%$ collapse). The indications for this procedure have been published in detail (5) and are similar to those for patients who would otherwise undergo a spinal fusion. Symptomatic internal disc disruption (IDD) should be deter- mined by concordant pain at the abnormal disc level, as well as, by the presence of a control disc injection on provocative discography (6). Many studies have discussed the significance of positive pain response on discography and its correlation with $\operatorname{IDD}(7,8)$.

Technique

The IDET procedure is performed in a similar fashion to diagnostic disc injections, except a flexible catheter with a heating element in the tip is passed through the needle (trocar) (9). This flexible thermal coil wraps around the inner surface of the annulus within the nucleus (Fig. 1). New catheter designs are being developed for more localized effects at the

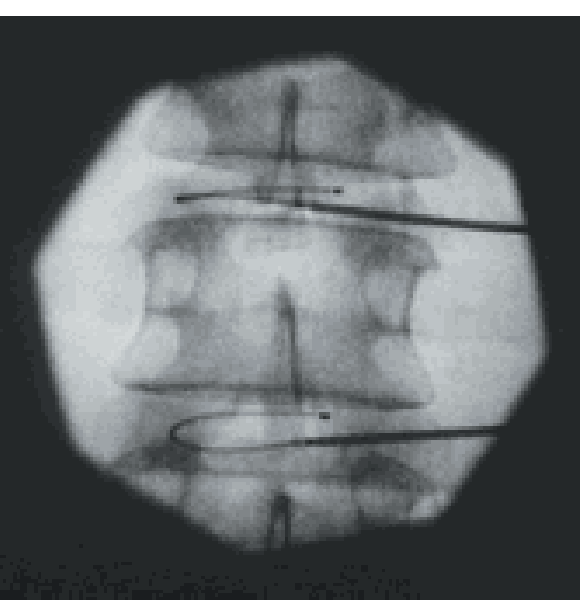

Fig 1. AP fluoroscopic image of two level IDET catheter placement with coil elements along ventral aspect of inner annulus 
site of focal disc protrusions. The catheter is gradually heated over a thirteen minute period to a maximum of $90^{\circ} \mathrm{C}$ and maintained at this temperature for four minutes (10). Bupivacaine and Cefazolin or Clindamycin are then instilled.

\section{Post-Procedural Care}

Post procedural care includes lumbosacral orthotic for six to eight weeks with limited work, sitting and driving activities, followed by low-intensity stabilization exercises for one month. Patients are asked to avoid strenuous and athletic activities for five to six months.

\section{Results}

Saal and Saal (5) demonstrated an improvement in $71 \%$ of patients on both the VAS and the SF-36 functional scales. In a 2002 Saal and Saal (11) two-year follow-up report, they noted fifty-three percent of their patients had at least a 21 point improvement in their SF-36 functional scale. Karasek and Bogduk (6), in 2000, reported fifty percent of their IDET group obtained greater than fifty percent relief using the VAS. Derby et al (12) reported $62.5 \%$ of IDET patients had a positive response based on several scales.

In a double blinded placebo controlled study, Pauza et al (13) showed a 2.4 point improvement in pain, using the visual analog scale, at six month follow up to IDET. The control group revealed only a 1.1 point improvement. There was also significant improvement in the mean Oswestry Disability scores. In a recent study Freeman et al (14) failed to show a significant change in any outcome measures at six month follow up to IDET. Both studies have not been published in a peer review journal (at the time of this writing).

\section{Complications}

Saal and Saal (5) reported no adverse events in their publications of this procedure. Others have reported cases of bacterial discitis, thermal nerve root injury, catheter breakage and a single report of intractable cauda equina syndrome.

\section{Percutaneous Laser Discectomy}

\section{Proposed Mechanism of Action}

Percutaneous laser discectomy is believed to cause a decrease in intradiscal pressure through vaporization of nuclear material by laser light, ultimately leading to diminished pain (15-17).

\section{Indications}

The indications for PLD are for the classic Mixter and Barr (18) herniated nucleus pulposus (posterolateral) with radicular pain, positive straight leg raise, and corroborating evidence on CT or MRI. This procedure is not indicated in the presence of stenosis, disc extrusion, disc sequestration or in patients with neurological deficits or previous surgery at same disc level, although the last is a relative contraindication (19).

\section{Technique}

An extra-pedicular approach comparable to that used for posterolateral discography is employed (20) to guide a trocar down through to the inner annulus. A laser fiber is then threaded into the nucleus pulposus at a distance of approximately one centimeter (19). A protocol of pulses and varying durations is then applied according to the type of laser light source and operator preference. The $\mathrm{LASE}^{\circledR}$ (Clarus-Medical, Minneapolis, MN) catheter, one design amongst a newer generation of laser discectomy instruments, employs the use of fluoroscopy as well as an in-line fiber optic for guidance of the laser tip (Fig. 2).

\section{Results}

Choy et al (21) employing Nd:YAG laser, obtained 78.4 percent good to fair results. Siebert (22) reported 78 percent good results with the Nd:YAG laser. Other researchers have noted results comparable to the above authors, performing laser discectomy with the KTP laser (23). Several studies have emphasized the importance of proper patient selection, including provocative discography, in significantly im- proving the success rate of percutaneous laser discectomy. Ohnmeiss, Guyer and Hochshuler (24) reported a 70.7\% success rate in patients with discography-supported contained disc herniation, versus a $44.4 \%$ success rate in those who either did not have discography or in whom contrast extravasation was seen.

\section{Complications}

Reported complications have included osteonecrosis and vertebral endplate injuries (25 26), nerve root injury (27), dural puncture, discitis (28), reflex sympathetic dystrophy (24), urinary retention (23), reflex ileus (29), hematomas, and abdominal perforations and cauda equina syndrome (30).

\section{Automated Percutaneous Discectomy OR APD}

\section{Proposed Mechanism of Action}

First described by Hijikata (31) in 1975, percutaneous discectomy was initially performed through a $5 \mathrm{~mm}$ cannula employing modified pituitary forceps. The modern-day automated percutaneous discectomy (APD) device removes nuclear material which decompresses the disc, thereby alleviating pain. Shea et al (32) have shown a decrease in intradiscal pressure at rest and when loaded, after application of the Nucleotome ${ }^{\circledR}$ (Clarusmedical, Minneapolis, MN). The Nucleotome ${ }^{\circledR}$ APD device employs a modified vitrectomy instrument with a reciprocating suction cutter to aspirate, cut and circulate fluid during discectomy (Fig. 3). Another device the Dekompressor ${ }^{\mathrm{TM}}$ (Stryker Instruments, Kalamazoo, MI) employs a rotating spiral channel which cuts and mobilizes nuclear material down the cannula into a receptacle chamber

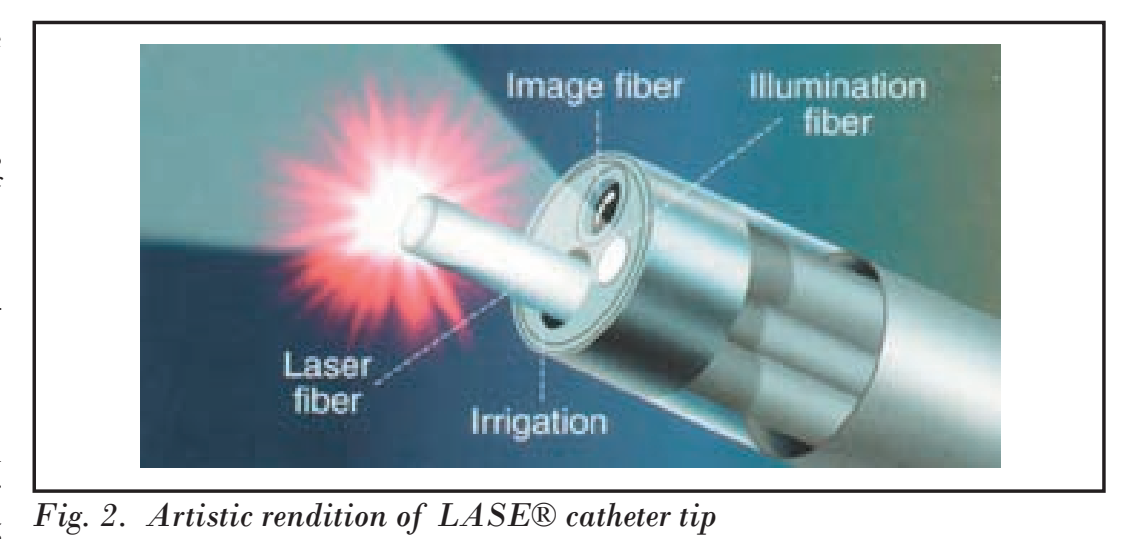




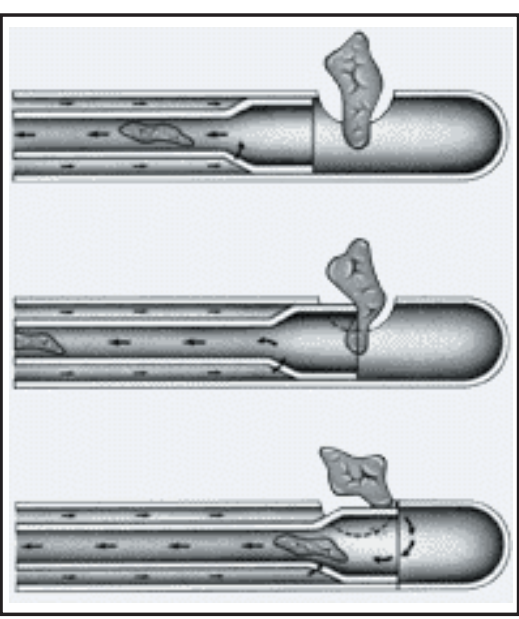

Fig. 3. Schematic drawing of Nucleotome ${ }^{\circledR}$ device with reciprocating cutting and suction tip

(Fig. 4). Both devices decrease intradiscal pressure by reducing the nuclear volume and thereby relieve pain.

\section{Indications}

The indications and contra-indications for percutaneous automated discectomy are the same as those for laser discectomy. Provocative discography with $\mathrm{CT}$ is recommended for pre-procedural evaluation. APD, like laser discecto$\mathrm{my}$, is recommended only for contained disc herniations. Onik and Davis (33) the original investigators of the Nucleotome ${ }^{\circledR}$ suggest four primary indications for this procedure. The first is far lateral disc herniations. The second is in young athletes. The third indication is for the treatment of discitis. The fourth indication is for recurrent disc herniations.

\section{Technique}

Employing an extra-pedicular approach, an 18-gauge needle with removable hub is passed down to the center of the nucleus. After positioning has been verified fluoroscopically, from several angles, a cannula with a tapered dilator is advanced to the annulus. The dilator is removed, with cannula in place. A trephine is employed to create an annulotomy. Then the trephine and needle are removed and the Nucleotome ${ }^{\circledR}$ device is advanced through the cannula to the center of disc. A protective stop prevents the APD device from advancing past mid-nucleus. Once the $\mathrm{Nu}$ cleotome ${ }^{\circledR}$ is engaged it aspirates fragments of nuclear material. The procedure is repeated with the patient in flexed and then

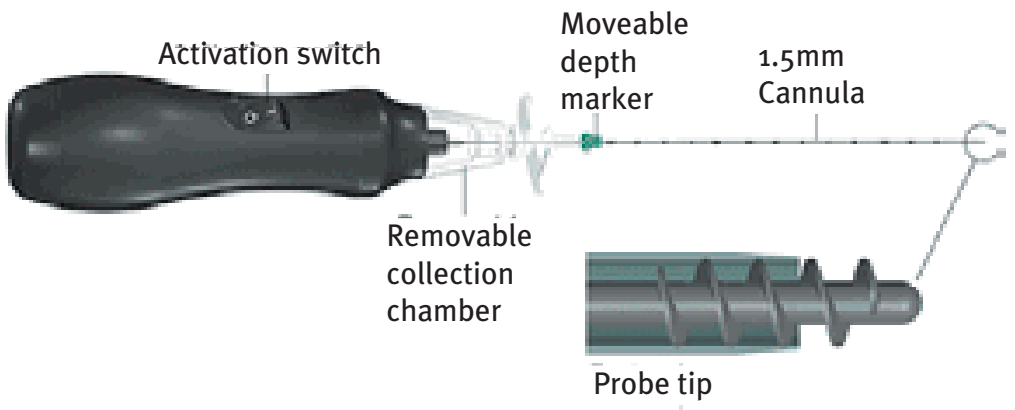

Fig. 4. Dekompressor ${ }^{\mathrm{TM}}$ percutaneous discectomy device with rotating spiral channel removes nuclear material and guides it down the cannula to a collection chamber

extended positions. Extirpation continues until only scant disc material is noted in the exiting irrigant line (a total device time of fifteen to thirty minutes).

\section{Results}

Although most reports are favorable, with outcomes comparable to laser discectomy, success rates for this procedure vary widely. Davis and Onik (34) reported a 78\% success rate in 200 consecutive patients. Other studies reveal success rates ranging from $37 \%$ to $87 \%$ $(35,36)$.

\section{Complications}

Some reported complications associated with percutaneous automated discectomy include discitis, psoas hematoma, retroperitoneal hematoma and a case of cauda equina syndrome (37-39).

\section{Disc Nucleoplasty ${ }^{\circledR}$}

\section{(Arthrocare Spine, Sunnyvale, CA)}

\section{Proposed Mechanism of Action}

An intradiscal catheter (Fig. 5) emits bipolar radiofrequency energy to the conductive nuclear material creating a highly charged ion particle or plasma field and consequent tissue dissociation (i.e., the formation of a tissue channel). On a molecular level, as the probe is advanced energized ions cause a lowtemperature cleavage of organic molecular bonds within the concentrated plasma field. This process of radiofrequency plasma ablation ${ }^{\circledR}$ or Coblation ${ }^{\circledR}$ causes a volumetric decrease in disc material and

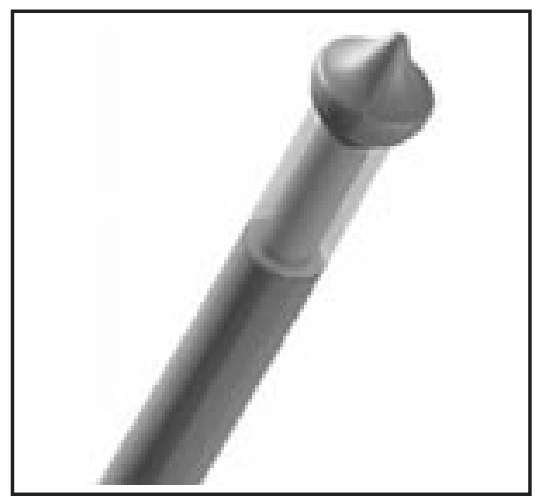

Fig. 5. DISC Nucleoplasty $®$ Perc-D catheter tip creates bipolar radiofrequency energy to cause low temperature cleavage of organic molecular bonds within the nuclear material

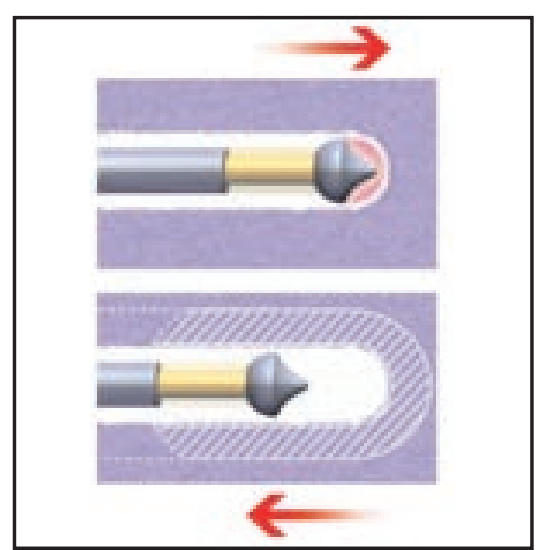

Fig. 6. DISC Nucleoplasty ${ }^{\circledR}$ Perc$D$ catheter tip causes coblation upon advancing into nuclear material and coagulation upon withdrawal 
has the advantage of causing little col- Results lateral tissue damage compared to conventional thermal cauterization. As the catheter or "wand" is withdrawn, the bipolar radiofrequency coagulates tissue adjacent to the channel (Fig. 6). The tissue channels created result in lowered intradiscal pressure and decreased pain. Recent studies have suggested a histochemical or anti-inflammatory mechanism behind the decrease in post procedure pain.

\section{Indications}

Nucleoplasty is indicated in contained disc herniations with positive straight leg raise and radicular symptoms although this procedure has also been offered to patients with internal disc disruption (without significant collapse of the interspace).

\section{Technique}

An extra-pedicular/posterolateral approach is applied to insert an intradiscal cannula and radiofrequency "wand." Advancing the wand allows the formation of a small controlled channel in the disc and withdrawal permits radiofrequency coagulation adjacent to the channel for decompression. Withdrawal, rotation and repeated advancement of the wand allows lesions to be created at the 2, 4, 6, 8, 10 and 12 o'clock positions (Fig. 7).
The success rate with this procedure lies at approximately eighty percent, based on studies by Singh et al (40). A recent study by Sharps and Zacharia (41) showed an overall success rate of $79 \%$ in all their subjects, with an $82 \%$ success rate in those who had not previously undergone surgical intervention. As with other minimally invasive procedures, studies have shown a significant decrease in intradiscal pressure after nucleoplasty on non-degenerated discs (42). This procedure has not, however, been shown to be very effective in decreasing intradiscal pressures in highly degenerated discs.

\section{Complications}

In general this procedure has proven to be very safe. Nirschl et al (43) reported the most common complaints at 24 hours post procedure to be pain at the procedure injection site, new numbness or tingling and pain in other areas of the back. At two weeks post procedure no patients complained of pain at the injection site or of new back pain. A small number of subjects (15\%) still had some residual numbness or tingling.

\section{SUMMARY}

A growing number of promising minimally invasive options to disc surgery are currently available. Despite the relative safety, high yielding success rates, and decreased healing time, the long term efficacy of these procedures is unknown, as most investigations have been open trials. Research and development of minimally invasive discectomy techniques should continue, since preliminary research seems to support the role of these procedures as effective and safe alternatives to major surgical intervention.

\section{Author Affiliation}

Joseph D. Fortin, DO

Medical Director

Spine Technology and Rehabilitation

7230 Engle Road, Suite \#210

Fort Wayne, IN 46804

E-mail: fortin@pol.net

\section{Adrian M. Zachary, DO}

Pain Fellow

Spine Technology and Rehabilitation 7230 Engle Road, Suite \#210

Fort Wayne, IN 46804

E-mail: zocya.zak@verizon.net

\section{REFERENCES}

1. Saal JS, Saal JA. Management of chronic discogenic low back pain with a thermal intra disco catheter. The preliminary report. Spine 2000; 25:382-388.

2. Shah RV, Lutz GE, Lee J et al. Intradiskal Electrothermal Therapy: A Preliminary Histologic Study. Arch Phys Med Rehabil 2001; 82: 1230-1236.

3. Bono C, Garfin S, Iki K et al. Temperatures within the lumbar disc and end plates during intradiscal electrothermal therapy: Formulation of a predictive temperature map in relation to distance from the catheter. Presented at ISIS 1oth Annual Scientific Meeting, Austin, TX, 2002.

4. Lee J, Lutz GE, Campbell D et al. Stability of the lumbar spine after intradiscal electrothermal therapy. Arch Phys Med Rehabil, 2001; 82:120-122.

5. Saal JA, Saal JS. Intradiscal electrothermal treatment for chronic discogenic low back pain. A prospective outcome study with minimum 1-year follow-up. Spine 2000 ; 25:2622-2627.

6. Karasek M, Bogduk N. Twelve month follow-up of a controlled trial of intradiscal thermal annuloplasty for back pain due to internal disc disruption. Spine 2000; 25 : 2601-2607.

7. Seghal N, Fortin JD. Internal disc disrup tion and low back pain. Pain Physician 2000; 3:143-157.

8. Fortin JD. Precision diagnostic disc injec tions. Pain Physician 2000; 3:271-288.

9. O’Neill, Derby R, Kenderes L. Precision injection techniques for diagnosis and treatment of lumbar disc disease. Seminars Spine Surg 1999; 11:104-118.

10. Saal JS, Saal JA. Thermal characteris- 
tics of lumbar disc coal and evaluation of a novel approach to targeted intradiscal thermal therapy. Presented at the 13th Annual Meeting of the North American Spine Society. San Francisco, CA, 1998.

11. Saal JA, Saal JS. Intradiscal Electrotherma Treatment for Chronic Discogenic Back Pain. Prospective outcome study with a minimum 2-year follow-up. Spine 2002; 27:9;966-974.

12. Derby R, Eck B, Chen $Y$ et al. Intradisca electrothermal annuloplasty (IDET): A novel approach for treating chronic discogenic back pain. Neuromodulation 2000; 3:6975.

13. Pauza K, Howell S, Dreyfuss P, et al. A randomized, double-blind, placebo controlled trial evaluating intradiscal electrothermal anuloplasty (IDET). In preceding of the annual meeting of the International Society for the Study of the Lumbar Spine, Vancouver, 2003.

14. Freeman BJC, Fraser RD, Cain CMJ, et al. A randomized controlled efficacy study: Intradiscal electrothermal therapy (IDET) versus placebo. In preceding o the annual meeting of the International Society for the Study of the Lumbar Spine, Vancouver, 2003.

15. Yunezawa T, Ononmura J, Kosaky R et al. System and procedure of percutaneous intradiscal laser nucleotomy, Spine 1990; 15:1175-1185.

16. Choy DSJ, Altman P. Fall of intradiscal pressure with laser ablation. Spine State Art Rev 1993; 7:23-29.

17. Prodoehl JA, Lane GJ, Black J et al. The effects of lasers on intervertebral disc pressures. Spine State Art Rev 1993; 7:17-21.

18. Mixter WJ, Barr JS. Rupture of the intervertebral disc with involvement of the spinal canal. N Engl J Med 1934; 211:210-215.

19. Quigley MR. Percutaneous laser discectomy. Neurosurg Clin North Am 1996; 7:3742.

20. Day PL. Lateral approach for lumbar discogram and chemonucleolysis. Clin Orthop 1969 67:90-93.
21. Choy DSJ, Case RB, Fielding W et al. Percutaneous laser nucleolysis of lumbar discs. N Engl J Med 1987; 317:771-772.

22. Siebert W. Percutaneous laser disc decompression: the European experience. Spine: State of the Art Reviews 1993; 7: 103-133.

23. Bosacco SJ, Bosacco DN, Berman AT et al. Functional results of percutaneous laser discectomy. Am J Orthop 1996; 25:825828 .

24. Ohnmeiss DD, Guyer RD, Hochschuler MD. Laser disc decompression. The importance of proper patient selection. Spine 1994; 19:2054-2059.

25. Cvitanic O, Schimandle J, Casper GD et al. Subchondral marrow changes after laser discectomy in the lumbar spine: $\mathrm{mr}$ imaging findings and clinical correlations. Am J Roentgenol. 2000; 174:1363-1369.

26. Tonami H, Masaaki K, Yasuaki K et al. MR imaging of subchondral osteonecrosis of the vertebral body after percutaneous laser diskectomy. Am J Roentgenol 1999; 173:1383-1386.

27. Epstein NE. Nerve root complications of percutaneous laser assisted discectomy performed at outside institutions: a technical note. J Spinal Disord 1994; 7:510512.

28. Choy DSJ, Ascher PW, Saddenki S. Percutaneous laser disc decompression. Spine 1992; 17:949-956.

29. Schatz SW, Talalla MB. Preliminary experience with percutaneous laser disc decompression in the treatment of Sciatica. Can J Surg 1995; 38:432-435.

30. Epstein NE. Laser-assisted diskectomy performed by an internist resulting in cauda equina syndrome. I Spinal Disord 1999; 12:77-79.

31. Hijikata S, Yamagishi M, Nakayama T et al. Percutaneous discectomy: A new treatment method for lumbar disc herniation. J Toden Hosp 1975; 5:5.

32. Shea M, Takeuchi TY, Wittenberg RH et al. Comparison of the effects of automated percutaneous diskectomy and conven- tional diskectomy on intra disco pressure, disc geometry and stiffness. J Spinal Disord 1994; 7:317-325.

33. Onik G, Davis W. Clinical experience in 250 cases with Nucleotome $\AA$. Presented at Automated Percutaneous Discectomy Course, New Orleans, LA, February 1990.

34. Davis GW, Onik G, Helms C. Automated percutaneous discectomy: A prospective multi-institutional study. Neurosurgery 1990; 26:228-233.

35. Kahanovitz N, Viola K, Goldstein T et al. A multicenter analysis of percutaneous diskectomy Spine 1990; 15:713-715.

36. Revel M, Payan C, Vallee C et al. Automated percutaneous lumbar diskectomy vs. chemonucleolysis in the treatment of sciatica. A randomized multi center trial. Spine 1993; 18:1-7.

37. Onik G, Mooney V, Maroon JC et al. Automated percutaneous diskectomy: A prospective multi-institutional study. Neurosurgery 1990; 26:228-233.

38. Maroon JC, Allen RC. A retrospective study of 1054 APLD cases: 820-month clinical follow-up at 35 U.S. centers. J NeurolOrtho Med Surg 1989; 10:335-337.

39. Onik G, Maroon JC, Jackson R. Cauda equine syndrome secondary to an improperly placed nucleotome probe. Neurosurgery 1992; 30:412-414.

40. Singh V, Piryani C, Liao K et al. Percutaneous disc decompression using Coblation (Nucleoplasty) in the treatment of discogenic pain. Pain Physician 2002; 5:250259.

41. Sharps LS, Zacharia I. Percutaneous disc decompression using Nucleoplasty ${ }^{\circledR}$. Pain Physician 2002; 5:121-126.

42. Chen YC, Lee SH, Chen D. Intradiscal pressure study of percutaneous disc decompression with nucleoplasty in human cadavers. Spine 2003; 28:661-665.

43. Nirschl M, Slipman CW, Zacharia et al. Preliminary data: Side effects and complications of lumbar nucleoplasty. Presented at the Annual Meeting of the International Spinal Injection Society, 2002. 
